\title{
Spinal cord stimulation and rehabilitation in an individual with chronic complete L1 paraplegia due to a conus medullaris injury: motor and functional outcomes at 18 months
}

\author{
Max O. Krucoff $\mathbb{D}^{1,2} \cdot$ Robert Gramer $^{3} \cdot$ Dana Lott $^{4} \cdot$ Emily Kale $^{4} \cdot{\text { Amol P. Yadav } \mathbb{D}^{5} \cdot \text { Muhammad M. Abd-El-Barr }}^{5} \cdot$ \\ Saurabh R. Sinha ${ }^{4}$. Shivanand P. Lad ${ }^{5}$
}

Received: 23 May 2020 / Revised: 15 September 2020 / Accepted: 21 September 2020

(c) International Spinal Cord Society 2020

\begin{abstract}
Introduction Epidural electrical stimulation of the conus medullaris has helped facilitate native motor recovery in individuals with complete cervicothoracic spinal cord injuries (SCI). A theorized mechanism of clinical improvement includes supporting central pattern generators intrinsic to the conus medullaris. Because spinal cord stimulators (SCS) are approved for the treatment of neuropathic pain, we were able to test this experimental therapy in a subject with complete L1 paraplegia and neuropathic genital pain due to a traumatic conus injury.

Case presentation An otherwise healthy 48-year-old male with chronic complete L1 paraplegia with no zones of partial preservation (ZPP) and intractable neuropathic genital pain presented to our group seeking nonmedical pain relief and any possible help with functional restoration. After extensive evaluation, discussion, and consent, we proceeded with SCS implantation at the conus and an intensive outpatient physical therapy regimen consistent with the recent SCI rehabilitation literature.

Discussion Intraoperatively, no electromyography (EMG) could be elicited with epidural conus stimulation. At 18 months after implantation, his motor ZPPs had advanced from L1 to L5 on the left and from L1 to L3 on the right. Qualitative increases in lower extremity resting state EMG amplitudes were noted, although there was no consistent evidence of voluntary EMG or rhythmic locomotive leg movements. Three validated functional and quality of life (QoL) surveys demonstrated substantial improvements. The modest motor response compared to the literature suggests likely critical differences in the anatomy of such a low injury. However, the change in ZPPs and QoL suggest potential for neuroplasticity even in this patient population.
\end{abstract}

These authors contributed equally: Max O. Krucoff, Robert Gramer

Supplementary information The online version of this article (https:// doi.org/10.1038/s41394-020-00345-7) contains supplementary material, which is available to authorized users.

Max O. Krucoff

maxkrucoff@gmail.com

1 Department of Neurosurgery, Medical College of Wisconsin, Wauwatosa, WI, USA

2 Department of Biomedical Engineering, Marquette University and Medical College of Wisconsin, Milwaukee, WI, USA

3 Department of Neurosurgery, Massachusetts General Hospital, Boston, MA, USA

4 Department of Neurology, Duke University Medical Center, Durham, NC, USA

5 Department of Neurosurgery, Duke University Medical Center, Durham, NC, USA

\section{Introduction}

Despite technological advancements, spinal cord injury (SCI) continues to leave patients with permanent impairments that prevent independence and diminish quality of life (QoL). As estimated in 2019, the average lifetime direct medical costs to care for a 25-year-old United States (US) citizen who sustains an SCI with resultant paraplegia is $\$ 2.5$ million (M), whereas individuals with tetraplegia require \$3.7-5.1 M [1]. In recent years, epidural electrical stimulation (EES) of spinal elements distal to a lesion (i.e., conus medullaris) has demonstrated previously untapped rehabilitative potential in individuals with chronic and complete motor lesions [2-7] —a subpopulation who have historically shown the least potential for further recovery [8-10]. Completely implantable spinal cord stimulators (SCS) and implantable pulse generators (IPG) are US Federal 
Drug Administration-approved for the treatment of neuropathic pain and are in widespread use [11, 12], and in several instances they have already been used to augment motor recovery in SCI rehabilitation [2-7]. The potential for synergistic application of EES with goal-oriented locomotor rehabilitation may provide a unique opportunity to significantly improve outcomes in this patient population, and recent evidence has generated excitement and optimism in the field [6, 7, 13-15].

As a treatment for neuropathic pain, SCS has found widespread use [11]. However, in the SCI population, no currently available treatments are consistently successful $[16,17]$. While the majority of people with SCI learn to cope with their pain over time [18], persistent pain in this population is known to significantly decrease QoL [19].

As an experimental therapy aimed at motor recovery, EES has been used in individuals with motor neuron disease for over 40 years, first showing its potential to enhance performance in humans with multiple sclerosis as early as 1973 [20-22]. Later, CPGs within the mammalian lumbosacral spinal cord were stimulated to produce locomotion $[23,24]$. Over the past several years, EES of the conus medullaris has been used to enable weight-bearing standing and locomotor-type stepping patterns in chronic American Spinal Injury Association Impairment Scale (AIS) level B [3] and A [2] patients. Other subjects with complete SCIs have regained the ability to selectively move their hips, knees, and ankles, as well as regain some coordination of flexor and extensor muscles [25, 26]. Using electrical techniques to generate stepping in combination with extensive goal-directed physical therapy (PT), individuals with chronic and complete SCIs have now shown the ability to develop positive functional plasticity and regain some voluntary control of lower extremity movement even after the stimulus was removed [5]. And even more recently, EES with extensive task-specific PT (over 80 sessions) has enabled bilateral stepping on a treadmill independent from assistance or bodyweight support and overground walking with a walker in a subset of patients with complete, chronic SCI during active stimulation [6, 7]. In addition to attaining better lower extremity control, improvements in cardiovascular, temperature, bladder, and bowel control have been reported, as well as enhanced sexual function in some [2, 3, 27]. In other subjects, subthreshold EES between L2 and $\mathrm{S} 1$, or direct stimulation of the pudendal nerve, has been shown to initiate micturition and/or improve reflexive voiding function [28-31].

To date, the published literature contains at least 13 subjects with motor paralysis who have been treated with tonic EES and have recovered some voluntary movement of their lower extremities [2-4, 6, 31-33]. It is theorized that individuals such as these who are most likely to benefit from EESaugmented rehabilitation will have a functional conus medullaris (the theorized location of locomotor CPGs in humans) [34], the presence of a "discomplete" SCI syndrome (evidence of anatomical and/or physiological continuity across a clinical complete lesion) $[35,36]$, and injuries that permit the application of EES below the lesion such that facilitated locomotor activity can be paired with cognitive intention to entrain trans-lesional plasticity [13, 14, 32, 37, 38]. Because our patient's injury pattern did not fit any of these descriptions yet we were able to provide a similar therapeutic regimen [2-4], this case serves as a direct but limited assessment of how critical such injury characteristics might be to achieving the previously reported results.

\section{Case presentation}

\section{Clinical history}

A 48-year-old male sustained a traumatic SCI and multilevel thoracolumbar fractures requiring a T8-L4 fusiondecompression 7 years prior to presenting to our hospital (Fig. 1). He had completed extensive in- and outpatient rehabilitation after his SCI, including numerous multimonth intensive inpatient sessions, until he had been told unanimously by his providers that his rehabilitation potential had been maximized. For the first 5 years post injury, he relied exclusively on a wheelchair for mobility. Eventually, the subject was able to regain very limited ambulatory mobility across short distances (a few feet) by using bilateral knee-ankle-foot orthoses and a walker with heavy reliance on circumductive compensatory movements. His MRI showed evidence of severe injury to the spinal cord centered at T12 and extending caudally and rostrally $\sim 1$ vertebral level in each direction (Fig. 1). The patient's neurological examination included normal motor strength and all-modality sensation down to L1 with completely absent sensation and motor strength below (L1 AIS-A). He had absent patellar and Achilles reflexes, no crossed adductor findings, negative bulbocavernosus reflex, reduced anal tone with no voluntary contraction (digital rectal examination scoring system [DRESS] rest score of 2 and squeeze score of 0) [39] and a mute Babinsky reflex. He was incontinent of urine and bowels. In addition to his functional limitations, the patient's most life-altering symptom was excruciating $\mathrm{S} 2 / 3$ genital pain that he describes as having felt like "constantly sitting on an electrical fence." To treat this, he had undergone sacral dorsal root ganglion (DRG) stimulator placement 1-year prior to his presentation. While this treatment initially achieved a 90-95\% pain reduction, his pain had been gradually returning. Therefore, he presented to us seeking further pain relief and anything that might help with functional and motor rehabilitation. 
Fig. 1 Presenting MRI and

X-ray. Clinical T2-weighted MRI (left) and lateral spine x-ray (right) showing the extent of the patient's injury and reconstruction before implantation of the epidural SCS.
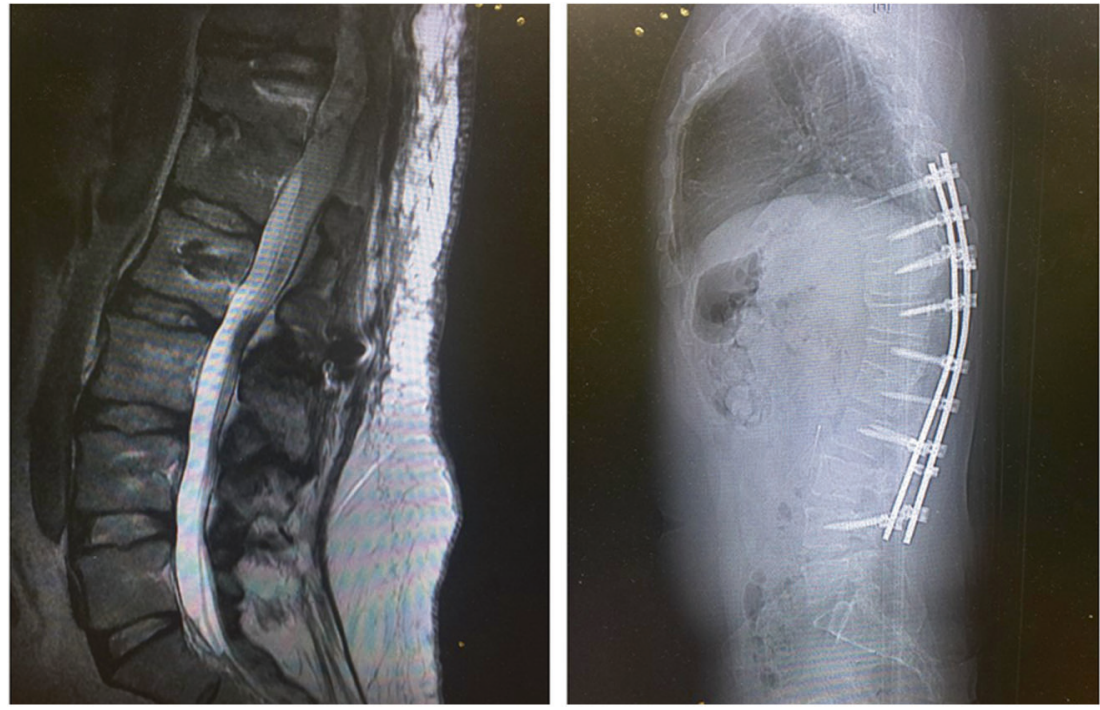

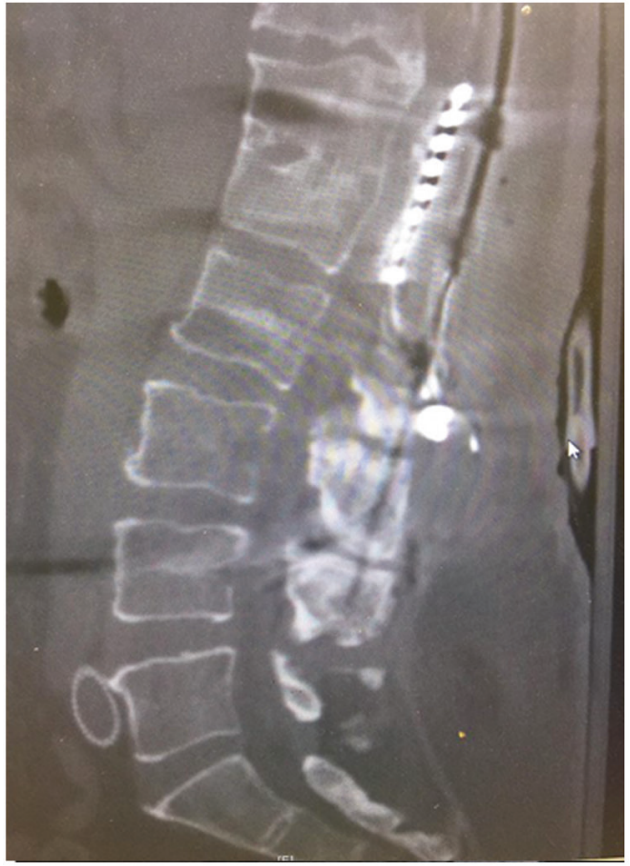

Fig. 2 Post-SCS Implantation CT Scan. Postoperative CT scan showing the placement of the paddle lead in the dorsal epidural space spanning T12-L1.

\section{Surgery}

After undergoing standard informed consent, the patient was taken to the operating room under general anesthesia with neuromonitoring and positioned prone. Fluoroscopic localization was used to the plan the incision and the dorsal laminae/bony fusion mass was drilled off to expose enough of the T12-L1 dorsal epidural space to place a 16contact paddle electrode $\left(\mathrm{Nevro}^{\circledR}\right)$ in a similar location to



Fig. 3 Paddle Lead Configuration and Settings. Paddle lead configuration (left) and initial settings (right).

recently published literature (Fig. 2) [2-4, 6]. Intraoperative stimulation was used to try to elicit lower extremity muscle activation as measured by free-running EMG; however, no EMG activity was seen at any combination of voltage, pulse width (PW), and frequency. The paddle was then secured with silk sutures and the leads were tunneled subcutaneously to an IPG (Nevro Senza $\mathrm{HF} 10^{\circledR}$ ) implanted in a subcutaneous pocket just below the patient's belt line.

\section{Programming}

Postoperative PT and stimulation were deferred for the first month to allow for incisional healing, resolution of surgical inflammation, and fibrotic anchoring of the paddle electrode to the target anatomy. Initial programming focused on the most caudal contacts $(7,8,15,16)$ at L1-L2 (Fig. 3). Because no EMG activity or sensory perception was elicited 
from any parameter combinations, initial settings were chosen based on literature values as follows: frequency $40 \mathrm{~Hz}$, PW $250 \mu$ s, amplitude $8 \mathrm{~mA}$ (Fig. 3) [3, 4]. The patient was given the option of keeping these settings or switching to another program with a frequency of $60 \mathrm{~Hz}$ and the same PW for motor rehabilitation, which he did on his own. He was also able to titrate the amplitude from 2.0 to $11.5 \mathrm{~mA}$. Additionally, the patient was given a "high-frequency overlay" program where he could receive stimulation at $10,000 \mathrm{~Hz}$ with a PW of $30 \mu$ s at $0.6 \mathrm{~mA}$ through the more rostral contact (1 and 2) for pain control while simultaneously receiving low frequency stimulation for motor rehabilitation through the caudal contacts. His low frequency stimulation remained on for the entire study period with minor exceptions, and there was no objective or subjective difference noted between the programs. Also, it should be noted that the patient's DRG stimulator settings remained stable for $>1$-year prior to study initiation and throughout the study period.

\section{Physical therapy}

The patient averaged about $10 \mathrm{~h}$ per week of rehabilitation for the majority of his post-SCI course. He had equipped his home gym with a treadmill, weight and resistance stations adapted for lower extremity exercise, and a bodyweight support system (LiteGait ${ }^{\circledR}$ ). Upon presenting to our clinic, the patient was given a home exercise program involving lower extremity and core strengthening exercises, including bridging with posterior pelvic tilt, side-lying hip flexion and hip extension, quadricep sets, gluteus sets, and supine hip adduction and adduction. The number of sets and repetitions progressed over the course of his therapy, as he tolerated up to three sets with repetitions based on his level of fatigue (between 12 and 15 repetitions). In addition to mat-level exercises, the patient utilized bodyweight support to assist overground and treadmill walking (Video 1), as well as an exercise peddler (Video 2). Following initiation of EES, he was gradually able to increase his fatigue-limited rehabilitation to an average of $20-30 \mathrm{~h} /$ week ( $3-4 \mathrm{~h} /$ day $)$.

\section{Electrophysiological assessments}

Electromyography (EMG) was recorded using either surface (initial evaluation) or needle (subsequent evaluations) electrodes placed on or in the following muscles (bilateral): gluteus maximus, rectus femoris, vastus lateralis, medial hamstrings, anterior tibialis, and gastrocnemius. For a subset of visits, surface electrodes were also placed in bilateral extensor carpi radialis and lower abdominal muscles. EMG was recorded on an amplifier with a sampling rate of $1 \mathrm{kHz}$ $\left(\mathrm{Natus}^{\circledR} \mathrm{EMU}^{\mathrm{TM}}\right)$. For display and analysis, the data were filtered at $20-500 \mathrm{~Hz}$ with a $60 \mathrm{~Hz}$ notch filter $\left(\mathrm{MATLAB}^{\circledR}\right.$ R2019B [MathWorks, Natick, MA]).

The subject was asked to activate different muscle groups on command, including ankle flexion/extension, knee flexion/extension, hip flexion/extension, and hip abduction/adduction. Lastly, the subject was asked to stand with the assistance of the bodyweight support device (LiteGait $\left.{ }^{\circledast}\right)$. EMG was recorded during attempted weight support on each leg, and then again with assisted ambulation. Each command/action was repeated.

For each movement, the pre-movement period (PRE) was defined as $2.5-0.5 \mathrm{~s}$ before the trigger. The movement period (POST) was defined as $0.5-2.5 \mathrm{~s}$ after the trigger. For each period, the EMG was rectified and the area under the curve was calculated. EMG activation was quantified in two ways: (1) ACTIVATION $=$ POST-PRE, and (2) \%ACTIVATION $=($ POST-PRE $) /$ PRE $\times 100 \%$.

For a subset of visits, somatosensory evoked potentials (SSEP) were recorded, per standard clinical protocol, in response to independent stimulation of the median nerves at the wrist or the tibial nerves at the ankles. Data were collected at a sampling rate of $48 \mathrm{kHz}\left(\right.$ Nicolet $^{\circledR}$ Viking $\left.^{\circledR}\right)$. A low frequency filter of $20 \mathrm{~Hz}$ and a high-frequency filter of $3000 \mathrm{~Hz}$ were used. Stimulation rate was $5.7 \mathrm{~Hz} ; 20-150$ responses were averaged for a trial and two trials were run for each evoked potential.

\section{Functional assessment}

Over the study period, three longitudinal surveys were administered: (1) Short Form Health Survey (SF-36), (2) Quality of Life Index $^{\odot}$ Spinal Cord Injury Version III (QOL-SCI), and (3) Spinal Cord Injury Independence Measure (SCIM). Each test was administered at a presurgical baseline (6 months prior to SCS implantation), prestimulation baseline (post-SCS implantation, while stimulation-naïve), and postmotor rehabilitation (18 months). Anal tone (assessed by DRESS), bowel and bladder incontinence, and sexual function were assessed at 0 and 18 months.

\section{Results}

\section{International Standards for Neurological Classification of Spinal Cord Injury (ISNCSCI) Assessment}

Preoperatively, the patient was assessed as an L1 AIS-A with no zones of partial preservation (ZPP) (Fig. 4a). At his 18-month post operative assessment, while the patient remained L1 AIS-A, he could now lift his bilateral hip flexors and knee extenders antigravity, and he had a flicker 

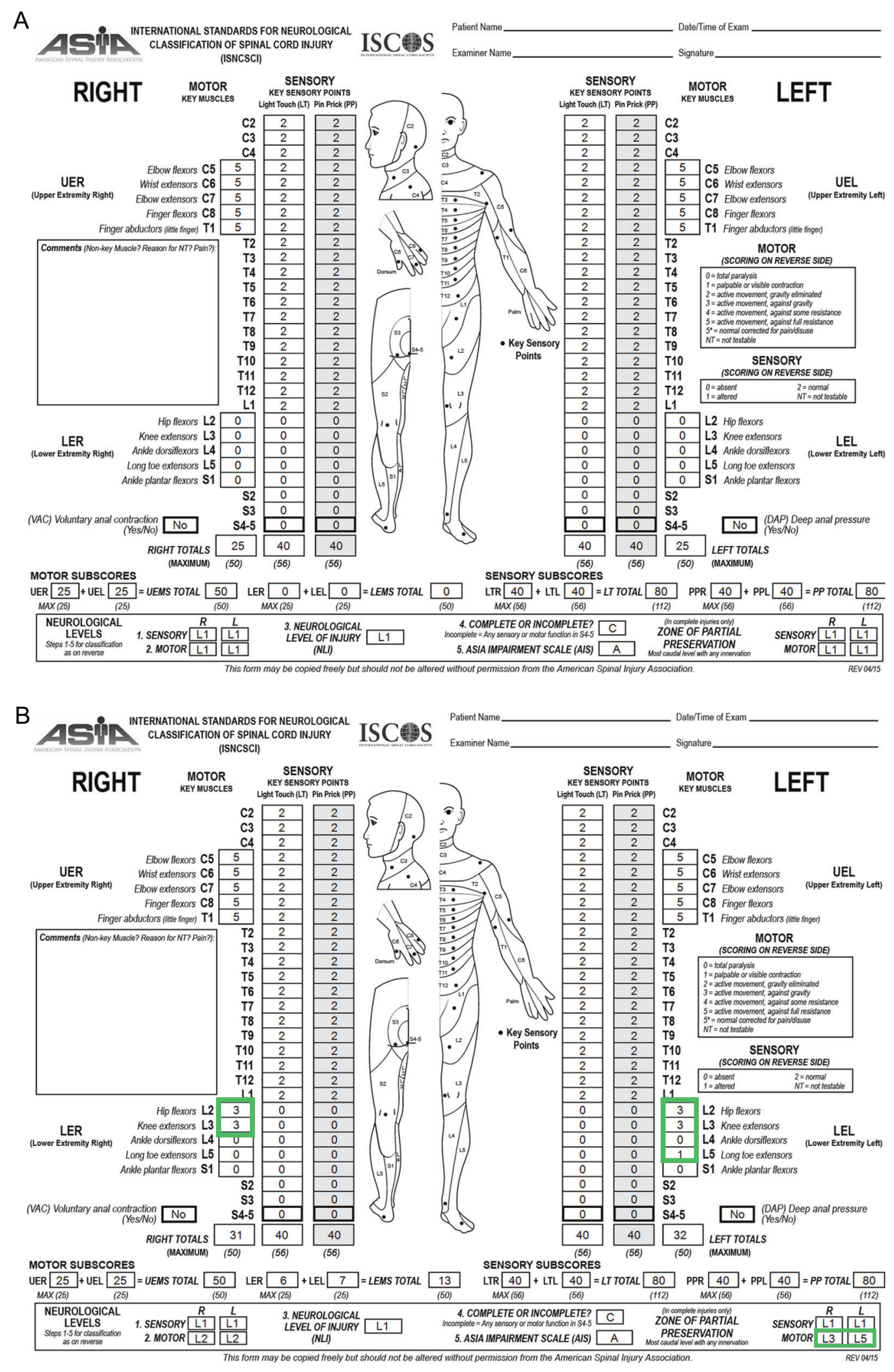

Fig. 4 ISNCSCI Assessments. a Preoperative and b 18-month post operative ISNCSCI assessments. The green circles denote areas of change. 
Fig. 5 Resting Lower

Extremity EMGs. Sample of resting lower extremity EMGs recorded preoperatively (left) and 14 months post operatively (right). A qualitative increase spontaneous activity can be noted in all lower extremity muscles on the 14-month post operative assessment compared to preoperatively. However, no evidence of voluntary EMG modulation could be elicited.
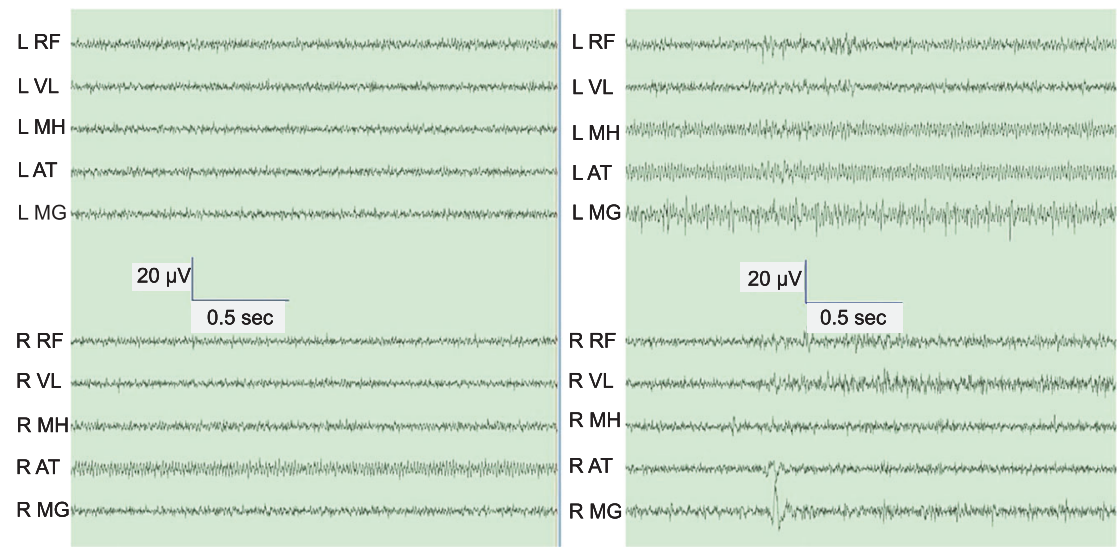

of movement in his left long toe extender. Therefore, his motor levels were assessed at L3 on the right and L5 on the left (Fig. 4b, Video 4). Sensory levels remained unchanged.

\section{EMG/SSEP}

Despite the change in AIS motor level assessment, all attempts to quantify voluntary muscle activation on EMG in the lower extremities were negative at 18 months (Video 3). As a control, voluntary extension of the wrists produced a 2000-3000\% increase in the area under the curve of the extensor carpi radialis EMG. However, qualitative evidence of increased spontaneous resting EMG amplitudes in virtually all measured lower extremity muscles did emerge (Fig. 5). All lower extremity SSEPs remained negative at the level of the spinal cord with normal peripheral nerve responses.

\section{Functional outcome}

Values for each of the three surveys can be seen in Tables 1-3. Overall, while results were similar across the baseline timepoints (pre- and postimplantation of SCS), marked improvements in the scores of all three assessments were noted after 18 months of motor rehabilitation with EES.

SF-36 consists of 8 domains normalized onto a $0-100 \%$ scale. $0 \%$ corresponds to maximal impairment and $100 \%$ corresponds to no impairment. Pre- and post-SCS implantation, the subject scored $25.8 \%$. After 18 months of stimulation and PT, he scored $64.1 \%$.

The QOL-SCI survey consists of 5 categories all normalized to a 0-30-point scale. 0 denotes complete dissatisfaction while 30 denotes complete satisfaction. Baseline scores were highly similar: 20.6 pre-SCS implant versus 20.8 post-SCS implant. After 18 months of SCS and PT, the score improved to 26.8. Notable increases occurred in "total quality of life" (16 and 16 at baselines to 26 following SCS) and "health and functioning" (8 and 9 at baselines to 23 following SCS).
Table 1 Short Form Health Survey (SF-36) results.

\begin{tabular}{lllc}
\hline & $\begin{array}{l}\text { Pre-SCS } \\
\text { implant }\end{array}$ & $\begin{array}{l}\text { Postimplant, } \\
\text { Pre-Stim }\end{array}$ & $\begin{array}{c}\text { Post- } \\
\text { Stim }\end{array}$ \\
\hline General health & 30 & 35 & 80 \\
Physical functioning & 5 & 5 & 40 \\
Role limitations, physical & 0 & 0 & 75 \\
Pain & 10 & 5 & 80 \\
Energy/fatigue & 30 & 35 & 75 \\
Social functioning & 37.5 & 37.5 & 75 \\
Emotional wellbeing & 60 & 60 & 88 \\
Role limitations, & 33.3 & 33.3 & 100 \\
emotional & & & \\
Composite & 25.8 & 25.8 & 64.1 \\
\hline
\end{tabular}

The SF-36 consists of 8 domains normalized onto a $0-100 \%$ scale. $0 \%$ corresponds to maximal impairment and $100 \%$ corresponds to no impairment.

Table 2 Quality of Life Index ${ }^{\odot}$ Spinal Cord Injury Version III (QOLSCI) results.

\begin{tabular}{llll}
\hline & $\begin{array}{l}\text { Pre-SCS } \\
\text { implant }\end{array}$ & $\begin{array}{l}\text { Postimplant, } \\
\text { Pre-Stim }\end{array}$ & $\begin{array}{l}\text { Post- } \\
\text { Stim }\end{array}$ \\
\hline Total quality of life & 16 & 16 & 26 \\
Health and functioning & 8 & 9 & 23 \\
Social and economic & 26 & 27 & 28 \\
Psychological/spiritual & 24 & 23 & 27 \\
Family & 29 & 29 & 30 \\
\hline
\end{tabular}

The QOL-SCI survey consists of 5 categories all normalized to a 0-30point scale. 0 denotes complete dissatisfaction while 30 denotes complete satisfaction.

The SCIM assesses three functional domains: self-care, respiration and sphincter management, and mobility. Each component is internally weighted based upon clinical relevance for a total sum of 100 ( 0 representing maximal dependency status, 100 representing complete independence). Overall baseline measures were equal (54), with an 
Table 3 Spinal Cord Injury Independence Measure (SCIM) results.

\begin{tabular}{llll}
\hline & $\begin{array}{l}\text { Pre-SCS } \\
\text { implant }\end{array}$ & $\begin{array}{l}\text { Postimplant, Pre- } \\
\text { Stim }\end{array}$ & $\begin{array}{l}\text { Post- } \\
\text { Stim }\end{array}$ \\
\hline Self-care & 15 & 15 & 16 \\
$\begin{array}{l}\text { Respiratory \& } \\
\text { sphincter }\end{array}$ & 26 & 26 & 29 \\
Mobility & 13 & 13 & 18 \\
Total & 54 & 54 & 63 \\
\hline
\end{tabular}

The SCIM assesses three functional domains self-care (feeding, grooming, bathing, and dressing), respiration and sphincter management (ventilatory status, catherization, bowel regimens, toileting), and mobility (bed and wheelchair transfers, ambulation, stair management). Each component is internally weighted based upon clinical relevance for a total sum 100 (0 representing maximal dependency status, 100 representing complete independence), divided into subscores of 20 for self-care, 40 for sphincter management, and 40 for mobility.

overall increase after 18 months of EES-augmented motor rehabilitation (63). Most notably, the subject's "respiratory \& sphincter" and "mobility" scores improved following 18 months of EES-augmented motor rehabilitation.

\section{Bowel, bladder, and sexual function}

Over the course of the study, the subject's anal tone improved from a 2 on the DRESS (mildly decreased tone) to a 3 (normal tone), and his bowel incontinence improved from 3-4 episodes per week to 2-3 episodes per month. He never regained voluntary anal contraction or deep anal pressure sensation, and he continued to rely completely on straight catheterization for urinary voiding. He did, however, endorse improved sensation of bladder fullness and relief from voiding at the end of the study. Regarding sexual function, the patient endorsed a subjective improvement in control of erection and ejaculation; however, this was not directly measured.

\section{Perineal pain}

Exacerbation of the patient's longstanding perineal pain (as well as newfound breakthrough bilateral lower extremity pain) with the introduction of SCS posed therapeutic challenges in using SCS for motor rehabilitation. Within hours of turning on stimulation, the patient experienced intense, dense paresthesias throughout all lumbar dermatomes with concomitant exacerbation of his perineal paresthesias. Ultimately, low amplitude stimulation over the most rostrally reaching contacts (T11) provided meaningful abatement of stimulationinduced leg pains and helped to reduce the chronic S2/3 pain. This was eventually adjusted to the high-frequency overlay outlined in the "Programming" section earlier. Transdermal clonidine was also used during periods of pain exacerbations and helped to reduce the frequency and severity of the patient's genital pain, enabling better adherence to SCS and motor rehabilitation over time.

\section{Discussion}

Current evidence supports the theory that individuals with complete SCI most likely to benefit from EES-augmented rehabilitation will have the following three components of their injuries: a functional conus medullaris, the presence of a discomplete SCI syndrome, and injuries that permit the application of EES below the lesion such that facilitated locomotor activity can be paired with cognitive intention to entrain trans-lesional plasticity [13, 14, 32, 37, 38]. The patient in this case had none of these features: he had an injured conus medullaris, no evidence of discomplete injury, and EES applied to the region of injury instead of below. Therefore, this case serves as a limited but direct assessment of the critical nature of such principles, which has not previously been tested. The relatively modest motor recovery, lack of rhythmic locomotor findings, and nonemergence of voluntary EMGs noted in this case compared to recently reported cases in the literature provides supportive evidence that these principles and injury characteristics are likely necessary prerequisites to obtaining the level of significant motor recovery previously reported [2-4].

One of the challenges inherent to treating injuries in this anatomical location is the high potential for "mixed" injury patterns (i.e., evidence of both upper and lower motor neuron injury, or conus medullaris and cauda equina syndromes) and interfering neuropathic pain, as was the case here. Therefore, several confounding factors are present which limit our ability to draw definitive conclusions about any individual contributing factor. For example, the lack of robust recovery may also be due to the presence of lower motor neuron (i.e., nerve root) injury, nonoptimized parameter settings, insufficient PT, unknown medication effects, interruption from neuropathic pain, and/or interference from the DRG or highfrequency overlay stimulation.

Despite these challenges, however, our patient did demonstrate larger resting state lower extremity EMGs, improved ZPPs, a slight increase in resting anal and (likely) bladder tone, as well as a substantial increase in his QoL compared to his preoperative baseline. This suggests that, even in this patient population, some positive neuroplasticity can be induced.

Interestingly, although our patient did obtain the ability to clinically extend his knees antigravity, voluntary EMGs were not able to be consistently confirmed in his quadriceps. This may be due to severe muscular atrophy and placement of the electrode needle in a noncontributing portion of the recovered muscle. Another possibility that cannot be ruled out is the development of a sub-clinically 
detectable spasticity that enabled antigravity movements with compensatory muscles; however, careful clinical assessments suggest this was not the case. More significant improvements may be seen from similar therapies applied to more subacute and incomplete injury cases and/or from more advanced forms of EES (e.g., coordinated spatiotemporal EES [40, 41]). Alternatively, patients who are unable to have rhythmic locomotion induced by EES of the conus may benefit from the addition of external therapies like exoskeletons [42, 43].

Regarding the patient's functional recovery, while the minimal clinically important difference (MCID) of serial SCIM measurements has been validated in acute to subacute SCI as a change $>12$ points in total score, $>3.3$ points in self-care, and $>1$ point for mobility, such a metric has not been established in the chronic SCI population to our knowledge [44]. However, it is reasonable to assume that in chronic SCI, scores would change less or not at all. In our case, the change in the subject's total and self-care scores (9 and 3, respectively) approached the MCID established in the acute setting, with the change in his mobility score exceeding it, thereby suggesting a likely clinically relevant difference. For the SF-36, a 3-5-point shift in each domain is generally considered to represent the MCID in chronic conditions [45]. For each of the eight domains, our subject reported improvements far exceeding this threshold. And for the QOLSCI survey, while it has been validated as a sound tool to quantify QoL, the MCID is yet to be established. In sum, the individual in this study demonstrated evidence of functional and QoL improvements across three standardized and validated assessments, suggesting a meaningful improvement.

\section{Limitations}

The most significant limitation of this experiment is the single case. Current opportunities to implant this patient population are exceedingly rare, which is why we present our 18-month results as a case report. As mentioned above, multiple confounding factors are present in our real-world case that limit our ability to draw definitive conclusions about any individual contributing factor to the patient's recovery in some areas and nonrecovery in others. In addition to what was previously mentioned, the relationship between pain modification and the emergences of ZPPs and resting EMGs cannot be completely and separately analyzed in this case. While sensory scores and SSEPs did not change, stimulation effects on anterolateral pathways were not entirely ruled out as contact heat evoked potentials were not assessed [46, 47]. Furthermore, this report does not attempt to separate the impacts of sensory, motor, or psychological factors of the EES-augmented therapy regimen presented here. Additionally, we do not attempt to draw conclusions regarding the efficacy, lack of efficacy, or superiority of any set of stimulation parameters over another. Because a majority of this patient's PT was completed on an outpatient basis, no analysis as to the relationship between his PT and parameter settings is attempted, nor is any claim made as to whether the type or intensiveness of PT may have been adequate. Despite these limitations, however, this case represents the first known report of EES-augmented rehabilitation in an individual with chronic complete paraplegia from a conus medullarislevel injury to our knowledge. It thereby provides the first look into what might be expected from an EES-augmented rehabilitation program in such patients.

Acknowledgements We would like to thank the individual who participated in these experiments, as well as his family and support team.

Funding Unrelated to this study, SRS receives research support from Eisai, inc., Marinus Pharmaceuticals, Monteris Inc., and UCB Pharamaceuticals. SRS is a consultant for Basilea Pharmaceutica, Monteris Inc., UCB Pharmaceuticals. SRS receives royalties from Springer from a previously published textbook. SPL is a consultant for Abbott Laboratories, Boston Scientific, Higgs Boson Health, Medtronic, Minnetronix, Nevro, and Presidio Medical.

\section{Compliance with ethical standards}

Conflict of interest The authors declare that they have no conflict of interest.

Consent for publication Informed consent was provided for publication of patient images and information.

Publisher's note Springer Nature remains neutral with regard to jurisdictional claims in published maps and institutional affiliations.

\section{References}

1. National Spinal Cord Injury Statistical Center. Facts and figures at a glance. Birmingham, AL: University of Alabama at Birmingham, 2020. www.msktc.org/sci/model-system-centers.\%0A, https://www. nscisc.uab.edu/Public/Facts and Figures 2020.pdf.

2. Angeli CA, Edgerton VR, Gerasimenko YP, Harkema SJ. Altering spinal cord excitability enables voluntary movements after chronic complete paralysis in humans. Brain. 2014;137:1394-409.

3. Harkema SJ, Gerasimenko Y, Hodes J, Burdick J, Angeli C, Chen $\mathrm{Y}$, et al. Effect of epidural stimulation of the lumbosacral spinal cord on voluntary movement, standing, and assisted stepping after motor complete paraplegia: a case study. Lancet. 2011;377:1938-47.

4. Grahn PJ, Lavrov IA, Sayenko DG, Van Straaten MG, Gill ML, Strommen JA, et al. Enabling task-specific volitional motor functions via spinal cord neuromodulation in a human with paraplegia. Mayo Clin Proc. 2017;92:544-54.

5. Rejc E, Angeli CA, Atkinson D, Harkema SJ. Motor recovery after activity-based training with spinal cord epidural stimulation in a chronic motor complete paraplegic. Sci Rep. 2017;7:1-12.

6. Gill ML, Grahn PJ, Calvert JS, Linde MB, Lavrov IA, Strommen JA, et al. Neuromodulation of lumbosacral spinal networks enables independent stepping after complete paraplegia. Nat Med. 2018;24:1677-82.

7. Angeli CA, Boakye M, Morton RA, Vogt J, Benton K, Chen Y, et al. Recovery of over-ground walking after chronic motor complete spinal cord injury. N Engl J Med. 2018;379:1244-50. 
8. El Tecle NE, Dahdaleh NS, Bydon M, Ray WZ, Torner JC, Hitchon PW. The natural history of complete spinal cord injury: a pooled analysis of 1162 patients and a meta-analysis of modern data. J Neurosurg: Spine. 2018;28:436-43.

9. Waters RL, Yakura JS, Adkins RH, Sie I. Recovery following complete paraplegia. Arch Phys Med Rehabilit. 1992;73:784-9.

10. Fawcett JW, Curt A, Steeves JD, Coleman WP, Tuszynski MH, Lammertse D, et al. Guidelines for the conduct of clinical trials for spinal cord injury as developed by the ICCP panel: spontaneous recovery after spinal cord injury and statistical power needed for therapeutic clinical trials. Spinal Cord. 2007;45:190-205.

11. Sdrulla AD, Guan Y, Raja SN. Spinal cord stimulation: clinical efficacy and potential mechanisms. Pain Pract. 2018;18:1048-67.

12. Bendersky D, Yampolsky C. Is spinal cord stimulation safe? A review of its complications. World Neurosurg. 2014;82:1359-68.

13. Krucoff MO, Miller JP, Saxena T, Bellamkonda R, Rahimpour S, Harward SC, et al. Toward functional restoration of the central nervous system: a review of translational neuroscience principles. Neurosurgery. 2019;84:30-40.

14. Krucoff MO, Rahimpour S, Slutzky MW, Edgerton VR, Turner DA. Enhancing nervous system recovery through neurobiologics, neural interface training, and neurorehabilitation. Front Neurosci. 2016;10:1-23.

15. Gad P, Gerasimenko Y, Zdunowski S, Turner A, Sayenko D, Lu DC, et al. Weight bearing over-ground stepping in an exoskeleton with non-invasive spinal cord neuromodulation after motor complete paraplegia. Front Neurosci. 2017;11:1-8.

16. Widerstrom-Noga EG, Duncan R, Felipe-Cuervo E, Turk DC. Assessment of the impact of pain and impairments associated with spinal cord injuries. Arch Phys Med Rehabilitat. 2002;83:395-404.

17. Cardenas DD, Nieshoff EC, Whalen E, Scavone JM. A randomized trial of pregabalin in patients with neuropathic pain due to spinal cord injury. Neurology. 2013;80:533-9.

18. Widerström-Noga EG, Felix ER, Cruz-Almeida Y, Turk DC. Psychosocial subgroups in persons with spinal cord injuries and chronic pain. Arch Phys Med Rehabilitat. 2007;88:1628-35.

19. Norrbrink Budh C, Österåker AL. Life satisfaction in individuals with a spinal cord injury and pain. Clin Rehabilitat. 2007;21:89-96.

20. Cook AW, Weinstein SP. Chronic dorsal column stimulation in multiple sclerosis. Preliminary report. N Y State J Med. 1973;73:2868-72.

21. Illis LSS, Sedgwick EMM, Oygar AEE, Awadalla MA. Dorsalcolumn stimulation in the rehabilitation of patients with multiple sclerosis. Lancet. 1976;307:1383-6.

22. Dooley DM, Sharkey J. Electrostimulation of the nervous system for patients with demyelinating and degenerative diseases of the nervous system and vascular diseases of the extremities. Appl Neurophysiol. 1977;40:208-17.

23. Grillner S. Neurobiological bases of rhythmic motor acts in vertebrates. Science. 1985;228:143-9.

24. Iwahara T, Atsuta Y, Garcia-Rill E, Skinner RD. Spinal cord stimulation-induced locomotion in the adult cat. Brain Res Bull. 1992;28:99-105.

25. Sayenko DG, Angeli C, Harkema SJ, Edgerton VR, Gerasimenko YP. Neuromodulation of evoked muscle potentials induced by epidural spinal-cord stimulation in paralyzed individuals. J Neurophysiol. 2014;111:1088-99.

26. Dimitrijevic MR, Danner SM, Mayr W. Neurocontrol of movement in humans with spinal cord injury. Artif Organs. 2015;39:823-33.

27. Gerasimenko Y, Gorodnichev R, Moshonkina T, Sayenko D, Gad P, Reggie Edgerton V. Transcutaneous electrical spinal-cord stimulation in humans. Ann Phys Rehabilitat Med. 2015;58:225-31.
28. Gad PN, Roy RR, Zhong H, Lu DC, Gerasimenko YP, Edgerton VR. Initiation of bladder voiding with epidural stimulation in paralyzed, step trained rats. PLoS ONE. 2014;9:1-9.

29. McGee MJ, Grill WM. Selective co-stimulation of pudendal afferents enhances bladder activation and improves voiding efficiency. Neurourol Urodyn. 2014;33:1272-8.

30. McGee MJ, Amundsen CL, Grill WM. Electrical stimulation for the treatment of lower urinary tract dysfunction after spinal cord injury. J Spinal Cord Med. 2015;38:135-46.

31. Herrity AN, Williams CS, Angeli CA, Harkema SJ, Hubscher CH. Lumbosacral spinal cord epidural stimulation improves voiding function after human spinal cord injury. Sci Rep. 2018;8:1-12.

32. Taccola G, Sayenko D, Gad P, Gerasimenko Y, Edgerton VR. And yet it moves: recovery of volitional control after spinal cord injury. Prog Neurobiol. 2018;160:64-81.

33. Gerasimenko Y, Lu D, Modaber M, Zdunowski S, Gad P, Sayenko D, et al. Noninvasive reactivation of motor descending control after paralysis. J Neurotrauma. 2015;13:1-13.

34. Bussel B, Roby-Brami A, Néris OR, Yakovleff A. Evidence for a spinal stepping generator in man. Paraplegia.1996;34:91-2.

35. Dimitrijevic MR. Neurophysiology in spinal cord injury. Paraplegia. 1987;25:205-8.

36. McKay WB, Lim HK, Priebe MM, Stokic DS, Sherwood AM. Clinical neurophysiological assessment of residual motor control in post-spinal cord injury paralysis. Neurorehabilit Neural Repair. 2004;18:144-53.

37. Wahl AS, Omlor W, Rubio JC, Chen JL, Zheng H, Schröter A, et al. Asynchronous therapy restores motor control by rewiring of the rat corticospinal tract after stroke. Science. 2014;344:1250-5.

38. van den Brand R, Heutschi J, Barraud Q, DiGiovanna J, Bartholdi K, Huerlimann M, et al. Restoring voluntary control of locomotion after paralyzing spinal cord injury. Science. 2012;336:1182-5.

39. Orkin BA, Sinykin SB, Lloyd PC. The digital rectal examination scoring system (DRESS). Dis Colon Rectum. 2010;53:1656-60.

40. Wagner FB, Mignardot JB, Le Goff-Mignardot CG, Demesmaeker R, Komi S, Capogrosso M, et al. Targeted neurotechnology restores walking in humans with spinal cord injury. Nature.2018;563:65-71.

41. Capogrosso M, Milekovic T, Borton D, Wagner F, Martin Moraud E, Mignardot J-B, et al. A brain-spinal interface alleviating gait deficits after spinal cord injury in primates. Nature. 2016;539:284-8.

42. Vouga T, Zhuang K, Olivier J, Lebedev M, Nicolelis M, Bouri M, et al. E $\Xi \mathrm{O}-\mathrm{a}$ brain-controlled lower limb exoskeleton for rhesus macaques. IEEE Trans Neural Syst Rehabilit Eng. 2017;4320:1-1.

43. Krucoff MO, Zhuang K, MacLeod D, Yin A, Byun YW, Manson $\mathrm{RJ}$, et al. A novel paraplegia model in awake behaving macaques. J Neurophysiol. 2017;118:1800-8.

44. Corallo V, Torre M, Ferrara G, Guerra F, Nicosia G, Romanelli E, et al. What do spinal cord injury patients think of their improvement? A study of the minimal clinically important difference of the Spinal Cord Independence Measure III. Eur J Phys Rehabilit Med. 2017;53:508-15.

45. Stewart AL, Greenfield S, Hays RD, Wells K, Rogers WH, Berry $\mathrm{SD}$, et al. Functional status and well-being of patients with chronic conditions: results from the medical outcomes study. JAMA. 1989;262:907-13.

46. Curt A, Ellaway PH. Clinical neurophysiology in the prognosis and monitoring of traumatic spinal cord injury. Handb Clin Neurol. 2012;109:63-75.

47. Kumru H, Soler D, Vidal J, Tormos JM, Pascual-Leone A, VallsSole J. Evoked potentials and quantitative thermal testing in spinal cord injury patients with chronic neuropathic pain. Clin Neurophysiol. 2012;123:598-604. 